\title{
Upside-Down and Inside-Out Signs in Uterine Inversion
}

\author{
Haruka Kawano a, Junichi Hasegawa ${ }^{a}$, Masamitsu Nakamura ${ }^{\text {a, c }}$, Daisuke Maruyama ${ }^{a}$, \\ Tatsuya Arakaki ${ }^{a}$, Ayako Ono $^{b}$, Yasufumi Miyake $^{b}$, Akihiko Sekizawa $^{a}$
}

\begin{abstract}
Uterine inversion is a rare condition that is accompanied by massive hemorrhaging and shock, resulting in a maternal emergency. The diagnosis of uterine inversion is often difficult due to massive postpartum hemorrhaging. Ultrasonography is useful for the diagnosis in such conditions, but we do not often encounter typical ultrasonographic images in uterine inversion because it occurs rarely. In the present case report of uterine inversion, we demonstrate the typical ultrasonographic findings of uterine inversion.
\end{abstract}

Keywords: Uterine inversion; Placenta accreta; Obstetric hemorrhage; Transabdominal ultrasound

\section{Introduction}

Uterine inversion is a rare condition that is accompanied by massive hemorrhaging and shock, resulting in a maternal emergency. Though a physical examination of uterine inversion typically reveals a mass-like uterine fundus in the vagina, the diagnosis of uterine inversion is often difficult due to massive postpartum hemorrhaging. Ultrasonography is useful for the diagnosis in such conditions. In the present case report, we demonstrate the typical ultrasonographic findings of uterine inversion.

\section{Case Report}

The case was a 39-year-old primiparous pregnant woman. She

Manuscript accepted for publication March 11, 2016

aDepartment of Obstetrics and Gynecology, Showa University School of Medicine, Tokyo, Japan

${ }^{b}$ Department of Emergency and Critical Care Medicine, Showa University School of Medicine, Tokyo, Japan

${ }^{\mathrm{c} C o r r e s p o n d i n g ~ A u t h o r: ~ M a s a m i t s u ~ N a k a m u r a, ~ D e p a r t m e n t ~ o f ~ O b s t e t r i c s ~ a n d ~}$ Gynecology, Showa University School of Medicine, 1-5-8 Hatanodai, Shinagawa-ku, Tokyo 142-8666, Japan. Email: mashamitsu1975@gmail.com

doi: http://dx.doi.org/10.14740/jocmr2538w had a history of endometrial polypectomy by a transcervical resectoscope. This pregnancy was achieved by intracytoplasmic sperm injection-embryo transfer. She was admitted to our maternity ward due to the onset of labor at 40 weeks of gestation and the labor course was uneventful. A healthy neonate weighing 3,900 $\mathrm{g}$ was delivered with Apgar scores of 8 and 9 at 1 and 5 min after delivery, respectively.

After delivery, since no symptom of natural placental separation for more than $15 \mathrm{~min}$ was observed, manual removal of the placenta with the Brandt-Andrew maneuver was attempted. During this procedure, lower abdominal pain and bleeding increased. At the same time, a transabdominal ultrasound demonstrated a fallen uterine fundus in the uterine body (Fig. 1a, upside-down sign), and immediately the patient fell into shock. Though manual reposition of the uterus was attempted, it was difficult because of the strong pain. We decided to attempt repositioning of the uterus in an operation room under anesthetized conditions, taking into account the possibility of placenta accrete/increta and the necessity of hysterectomy. The total amount of bleeding until then was $1,800 \mathrm{~mL}$. Her blood test results were as follows: hemoglobin $6.8 \mathrm{~g} / \mathrm{dL}$; hematocrit $20.1 \%$; platelet $8.7 \times 104 / \mu \mathrm{L}$; fibrinogen $125 \mathrm{mg} / \mathrm{dL}$; FDP $15.55 \mu \mathrm{L} / \mathrm{mL}$ and D-dimer $8.00 \mu \mathrm{L} / \mathrm{mL}$.

When the patient was transferred to the operation room, her blood pressure was 42/21 $\mathrm{mm} \mathrm{Hg}$ and her pulse was 140 beats per minutes (bpm). At this time, a blood gas analysis showed the following results: $\mathrm{pH} 7.164 ; \mathrm{pCO}_{2}, 35.5 \mathrm{~mm} \mathrm{Hg}$; $\mathrm{pO}_{2} 575.3 \mathrm{~mm} \mathrm{Hg} ; \mathrm{HCO}_{3} 12.5 \mathrm{~mm} \mathrm{Hg}$ and BE -14.7. The patient was promptly intubated. Since massive bleeding continued, we decided to perform a temporary aortic occlusion using an intra-aortic occlusion catheter to achieve hemostasis. An intra-aortic balloon occlusion (IABO) procedure was immediately performed without fluoroscopy by an emergency physician. The balloon was then inflated, and the blood pressure immediately increased to $104 / 53 \mathrm{~mm} \mathrm{Hg}$.

During the recovery after IABO inflation under anesthetized conditions, reposition of the uterus was successfully performed. Nevertheless, bleeding continued because the placenta had not become separated and was still firmly attached to the uterus. Therefore, we decided to manually remove the placenta. However, the procedure failed, resulting in the inside of the uterine fundus completely protruding the outside of the vagina with the adhered placenta. A transabdominal ultrasound at the same time showed that the complete inverted uterus was displaced downward toward the vagina (Fig. 1b, 

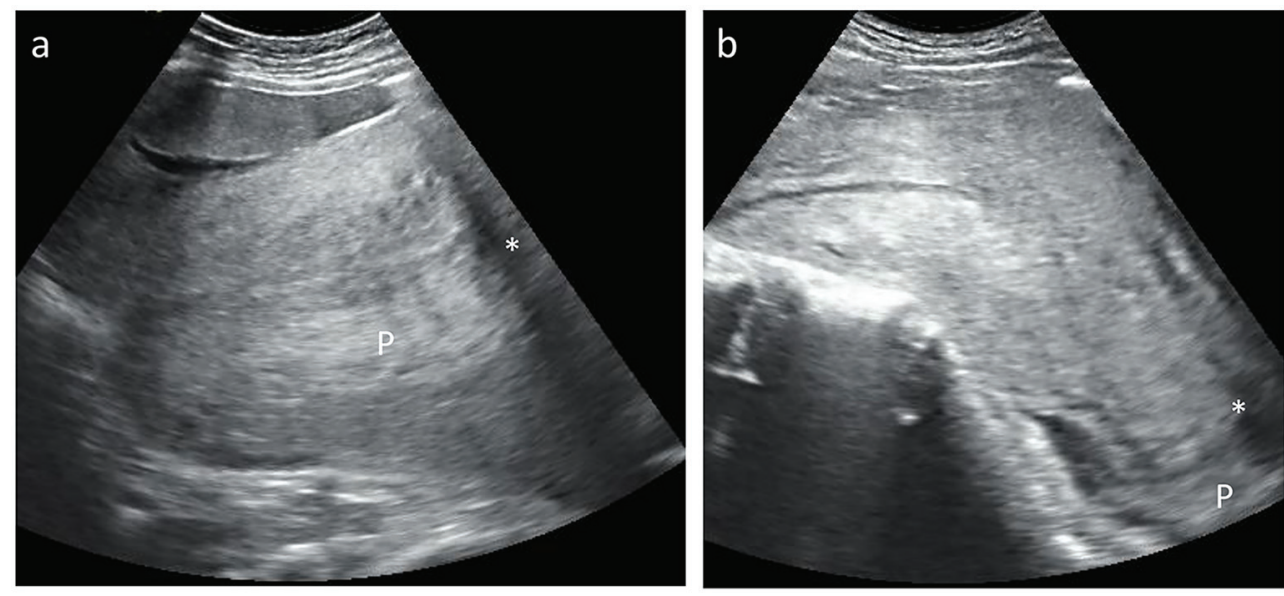

Figure 1. Transabdominal ultrasound pictures of uterine inversion. (a) Incomplete uterine inversion. A fallen uterine fundus ${ }^{*}$ ) with placenta $(P)$ in the uterine body was visualized (upside-down sign). (b) Complete uterine inversion. The inverted uterus displaced downward toward the vagina was visualized (inside-out sign).

inside-out sign). Hysterectomy was decided due to the diagnosis of placenta increta. The operation was successfully performed with an operating time of $1.5 \mathrm{~h}$ and the blood loss during the operation was $3,290 \mathrm{~mL}$. The total blood loss was estimated to be more than $7,000 \mathrm{~mL}$, and 18 units of RBCs and 12 units of FFP were transfused. The postoperative course was uneventful and the patient was discharged on postoperative day 7.

\section{Discussion}

The chance to encounter typical ultrasonic images of uterine inversion is very rare since the incidence of uterine inversion was previously reported to range from 1 in 1,200 to 57,000 deliveries [1-3]. Several risk factors for uterine inversion, such as placenta accreta, a short umbilical cord, augmentation, excessive extension of the uterine muscle, rough procedures (e.g., the Crede maneuver, excessive cord traction and manual removal of the placenta without sign of placenta separation and well contraction of the uterus) for placental removal, have been previously reported [4]. In the present case, we speculated that placenta increta induced uterine inversion. However, despite that $57 \%$ of cases with uterine inversion reportedly occur in low-risk women [3], every caregiver in the delivery room is required to look for this rare condition. A delay in the diagnosis of uterine inversion might result in critical bleeding and severe maternal hemorrhagic shock.

An ultrasonographic assessment of the uterus is a relatively easy procedure for detecting uterine inversion. Regarding the differential diagnosis of postpartum massive hemorrhaging, ultrasonic findings of the upside-down and inside-out signs should be considered.

\section{Ethical Consideration}

All procedures were conducted in accordance with the ethical standards of the responsible committee on human experimentation (institutional and national) and the Helsinki Declaration of 1975, as revised in 2008. Informed consent was obtained the patient.

\section{Conflicts of Interest}

The authors declare no financial or other relations that could lead to a potential conflict of interest.

\section{References}

1. Morini A, Angelini R, Giardini G. [Acute puerperal uterine inversion: a report of 3 cases and an analysis of 358 cases in the literature]. Minerva Ginecol. 1994;46(3):115127.

2. Baskett TF. Acute uterine inversion: a review of 40 cases. J Obstet Gynaecol Can. 2002;24(12):953-956.

3. Witteveen T, van Stralen G, Zwart J, van Roosmalen J. Puerperal uterine inversion in the Netherlands: a nationwide cohort study. Acta Obstet Gynecol Scand. 2013;92(3):334-337.

4. Mirza FG, Gaddipati S. Obstetric emergencies. Semin Perinatol. 2009;33(2):97-103. 